Wirshing, 1989); perhaps particularly unless emphasis is laid on training and monitoring AIMS examiners. Pseudoparkinsonism and akathisia would be expected to be more common on haloperidol.

Further studies comparing the TD risk of atypical and conventional antipsychotic medications are needed.

Beasley, C. M., Dellva, M. A., Tamura, R. N., et of (1999) Randomised double-blind comparison of the incidence of tardive dyskinesia in patients with schizophrenia during long-term treatment with olanzapine or haloperidol. British journal of Psychiatry. 174. 23-30

Cummings, J. L. \& Wirshing, W. C. (1989) Recognition and differential diagnosis of tardive dyskinesia. International journal of Psychiatry in Medicine, 19. 133-144.

Clazer, W. M., Morgenstern, H. \& Doucette, J.T. (1993) Predicting the long-term risk of tardive dyskinesia in outpatients maintained on neuroleptic medications. Journal of Clinical Psychiatry, 54, 133-139.

Munetz, M. R. Cornes, C. L. (1983) Distinguishing akathisia and tardive dyskinesia: a review of the literature. Joumal of Clinical Psychopharmocology, 3. 343-350.

Schooler, N. R. \& Kane, J. M. (1982) Research diagnoses for tardive dyskinesia. Archives of General Psychiatry, 39, 486-487.

S.W. Woods Department of Psychiatry, Yale University School of Medicine, 34 Park Street, Room B38, New Haven, CT 06519, USA

Author's reply: We appreciate the opportunity to respond to several interesting points raised by Dr Woods in his letter regarding our recent article (Beasley et al, 1999).

Dr Woods suggests the possibility that the reported difference in rates of development of tardive dyskinesia (TD) may have been due to the insensitivity of the assay procedure (periodic administration of the Abnormal Involuntary Movement Scale (AIMS)) to "true TD". The letter further suggests that this may have been due to the lack of systematic rater training and/or lack of interrater reliability. It is true that raters were not trained systematically nor was interrater reliability evaluated. However, for these hypotheses to be tenable, the insensitivity would have been selective for the olanzapine treatment group. Low interrater reliability is generally believed to increase variability in a random fashion and thereby create a situation where differences are more difficult to detect owing to this source random error. Further, with the haloperidol treatment group, there was clearly substantial sensitivity with our assay procedure as discussed and addressed at length in our article.

As noted in the letter, the comparison of baseline prevalence of TD detected in our study and the estimates of point prevalence for TD in the population of patients suffering from schizophrenia and with demographic characteristics similar to those of our research sample affords a method to judge the validity of our assay procedure for TD. The percentage of patients identified as having TD at baseline in our study population (defined as meeting SchoolerKane criteria or having a history of TD recorded on their charts) was $28.8 \%$. Kane et al (1988) found a point of prevalence of $23.4 \%$ across three sites. Additional studies and reviews suggest a prevalence of about $20 \%$ among patients with schizophrenia (Kane et al, 1980; Kane \& Smith, 1982). Our baseline prevalence and the point prevalence of TD cited in the literature are comparable, suggesting at least good reliability between investigators conducting our study and the raters generating the point prevalence data in the literature described above. If the point prevalence data cited in the literature are accepted as accurately describing the point prevalence of "true TD", the concordance also suggests the validity of the ratings of our investigators.

We have acknowledged that cases identified during the initial six-week examination period may have been identified because of confounding of withdrawal phenomena. The possibility also exists that AIMS ratings were confounded by akathisia and/or parkinsonism. Dr Woods suggests that an analysis excluding that initial study period would be useful. Although not displayed graphically, such an analysis was included in Tables 1 and 3 and indicates a clear difference between olanzapine treatment and haloperidol treatment. Also, although the data were not included in the article, Barnes Akathisia Scale (Barnes, 1989) and Simpson-Angus Scale (Simpson \& Angus, 1970) scores correlated poorly with the AIMS scores in our study.

We believe that we cautioned the readers of our article not to accept the absolute rate of development of TD found in our study as necessarily valid. However, the relative differences between rates of development of TD during olanzapine and haloperidol treatments in these large samples of patients would appear well established and valid.

We agree that further studies of the incidence and rate of development of TD in patients treated with typical compared with atypical antipsychotics is warranted.
It would be useful to standardise frequency of observation and optimise validity and relativity of assay methods.

Barnes, T. R. E. (1989) A rating for drug-induced akathisia. British journal of Psychiatry, 154, 672-676.

Beasley, C. M., Dellva, M. A., Tamura, R. N., et of (1999) Randomised double-blind comparison of the incidence of tardive dyskinesia in patients with schizophrenia during long-term treatment with olanzapine or haloperidol. British journal of Psychiotry 174, 23-30.

Kane, J., Wogner, J., Stenzler, S., et al (1980) The prevalence of presumed tardive dyskinesia in psychiatry inpatients and outpatients. Psychophormocology, 69. 274-251.

- Smith, J. M. (1982) Tardive dyskinesia: prevalence, incidence and risk factors, 1959 to 1979. Archives of General Psychiatry, 39, 473-481.

—, Woerner, M. L Lieberman, J. (1988) Tardive dyskinesia: prevalence, incidence, and risk factors. Journal of Clinical Psychoparmacology, 8 (suppl.), 52S-56S

Simpson, G. M. A Angus, J.W. S. (1970) A rating scale for extrapyramidal side effects. Acto Psychiatrico Scondinavico, 21 (suppl.), SII-SI9.

C. M. Beasley Eli Lilly and Company, Lilly

Corporate Center, Indianapolis, IN 46285, USA

\section{Atypical antipsychotics and neuroleptic malignant syndrome}

Sir: We were interested to read the article by Barnes \& McPhillips (1999), particularly the paragraph about neuroleptic malignant syndrome (NMS) in which it was suggested that the newer atypicals (sertindole, olanzapine and quetiapine) have not been associated with NMS.

We are sorry to note that this is not the case. Presumably since the above article went to press, there have been at least two case reports of NMS in association with olanzapine (Filice et al, 1998; Burkhard et al, 1999) in which olanzapine was the only neuroleptic used. With regard to quetiapine we are informed (Zeneca, personal communication, 1998) that their internal safety database has established possible and definite cases of NMS associated with quetiapine usage.

Although the atypicals have been rightly celebrated for their efficacy and side-effect profiles, any drug whose mechanism of action involves the blockade and downregulation of central dopamine receptors should be regarded as a potential cause of NMS. Clinicians should maintain as great a vigilance with the atypical neuroleptics as with the older, traditional ones. 
Barnes, T. R. E. \& McPhillips, M. A. (1999) Critical analysis and comparison of the side-effect and safety profiles of the new antipsychotics. British journal of Psychiatry, 174 (suppl. 38), 34-43.

Burkhard, P. R., Vingerhoets, F. J. G., Alberque, C., ot al (1999) Olanzapine induced neuroleptic malignant syndrome. Archives of General Psychiatry, 56, 101-102.

Fillce, G. A., McDougall, B. C., Ercan Fang, N., < of (1998) Neuroleptic malignant syndrome associated with olanzapine. Annals of Pharmacotherapy, 32. 1158-1159.

D. Kohen 2nd Floor East Wing, Homerton Hospital, Homerton Row, London E9 6SR

M. F. Bristow Cheam Resource Centre, 671 London Road, North Cheam, Surrey SM3 9DL

\section{Prescribing donepezil in clinical practice}

Sir: We were interested to read the recent editorial on the new treatments for Alzheimer's disease and the account of experiences with these drugs in south Manchester (Burns et al, 1999a). We report here our success in titrating up the dose of donepezil and difficulties in discontinuing treatment.

In Lancaster we have been prescribing donepezil since April 1997 using the Cambridge Cognitive Examination (part of the Cambridge Examination for Mental Disorders of the Elderly; Roth et al, 1986), the Clinicians' Interview-Based Impression of Change (Leber, 1990) and carer report to assess response. We have prescribed for 44 patients so far. The pattern of response has been very similar to that in south Manchester and we can confirm valuable noncognitive response such as improved mood, initiative, confidence and clarity of thought. However, we have had only five drop-outs (in south Manchester one-third of patients dropped out) and we wonder whether our individually tailored flexible way of prescribing donepezil has meant that side-effects were less problematic. We have aimed at $10 \mathrm{mg}$ daily as the optimum dose in all cases in view of the clear doseresponse effect, recently confirmed (Burns et $a l, 1999 b$ ). Using the long half-life (70 hours) of donepezil, it is easy to titrate up slowly from $5 \mathrm{mg}$ to $\mathbf{1 0} \mathrm{mg}$ daily, by using intermediate steps, such as 5, 5, 10 (repeated) $5,10,10$ (repeated) to achieve 10 , 10,10 over weeks. It is important, therefore, that the first prescription for $10 \mathrm{mg}$ daily is dispensed as $2 \times 5 \mathrm{mg}$ to allow for this, and also to allow for a dose reduction to $5 \mathrm{mg}$ daily, if side-effects are really troublesome. If morning diarrhoea is a problem after $10 \mathrm{mg}$ nocte, $5 \mathrm{mg}$ twice daily has resolved the problem.

Another difference from the south Manchester experience is that we have had some problems discontinuing donepezil. In three cases discontinuation has been followed by some of the following: increased disorientation with loss of familiarity, agitation and restlessness, especially nocturnal, with visual hallucinations, lowering of mood, anxiety, uncooperativeness and carer distress. In future, we plan to reduce the dose to $5 \mathrm{mg}$ some weeks prior to stopping it altogether.

We wonder whether these new anticholinesterase drugs may have a role in future as an alternative to neuroleptics in managing behavioural disturbance associated with Alzheimer's disease.

Burns, A., Russedl, E. \&age, S. (1999a) New drugs for Alzheimer's disease. British journal of Psychiotry, 175. $476-479$.

-, Rossor, M., Hecker, J., et al and the International Donepedil Study Group (1999b) The effects of donepezil in Alzheimer's disease - results from a multinational trial. Dementia and Geriatric Cognitive Disorders, 10, 237-244.

Leber, P. (1990) Guidelines for the Clinical Evaluation of Antidementia Drugs. Washington, DC: Food and Drug Administration.

Roth, M., Tym, E., Mountjoy, C. Q., et al (1986) CAMDEX. A standardised instrument for the diagnosis of mental disorder in the elderly with special reference to the early detection of dementia. British journal of Psychiatry, 149, 698-709.

M. A. Watts-Tobin Department of Old Age Psychiatry, Lancaster Moor Hospital, Lancaster LAI 3JR

N. Horn University of Manchester Neuroscience and Psychiatry Unit, Stopford Building, Oxford Road, Manchester MI3 9PT

\section{More trouble with ethics committees}

Sir: I applied for permission to conduct research within two National Health Service trusts, each covered by two local research ethics committees (LRECs). The responses were: (a) trust 1: one LREC approved, the other refused on the grounds that the study contravened the Data Protection Act; (b) trust 2: one LREC approved, the other approved on condition that patient consent was obtained. I attempted to clarify: first, how to proceed, given these contradictory decisions; second, why consent was required (given that the intention was to obtain anonymised patient information from clinicians without patient contact) and third, whether or not the information required contravened the Data Protection Act.

According to the health authority, the situation arose because LRECs had failed to merge alongside their corresponding trusts. The health authority also noted that I need only have applied to one LREC per trust, although this was not clarified on application. The health authority advised me to request information about only those patients who resided in geographical areas covered by the LRECs who gave approval. Notwithstanding the effects on the study, this meant telling clinicians in trust 1 that it was only ethical for them to give information about patients from certain geographical areas, and in trust 2 that only those patients from certain geographical areas need to consent. The Department of Health and the health authority could not advise about the consent issue and noted that decisionmaking had been devolved entirely to the LRECs. The Data Protection Registrar's office commented that the information I required did not contravene the Data Protection Act.

It has long been recognised that LRECs demonstrate high degrees of practical and methodological diversity (Garfield, 1995; Middle et al, 1995). Although it must be accepted that there will be some variation due to local needs (Gilbert et al, 1989), it is reasonable to expect that LRECs, particularly those covering the same local area, will strive for both internal and external consistency. The Department of Health, research councils and the Data Protection Registrar should work together to provide national guidelines for LRECs, both in the public interest and in the interests of research. The LRECs involved in my case have now decided to review their procedures, but too late to benefit my study.

Garfield, P. (1995) Cross district comparison of applications to research ethics committees. British Medical journal, 311, 660-66I.

CIIbert, C., Fulford, K. W. M. \& Parber, C. (1989) Diversity in the practice of district ethics committees. British Medical journal, 299, 1437-1439.

Middle, C., Johnsoon, A., Petty, T., et of (1995) Ethics approval for a national postal survey: recent experience. British Medical Journal, 311, 659-660.

A. Cohen Department of Clinical Psychology, Salomons Centre, Broomhill Road, Southborough, Tunbridge Wells, Kent TN3 0TG 